\title{
Comunicação Organizacional, entre Apolo e Dionisio
}

\author{
Organizational Communication, \\ between Apollo and Dionysus
}

\author{
Comunicación Organizacional, \\ entre Apolo y Dioniso
}

\section{Paulo Nassar}

- Doutor e Mestre em Ciências da Comunicação pela Escola de Comunicações e Artes da Universidade de São Paulo (ECA-USP)

- Professor do Curso de Relações Públicas e do Programa de Pós-Graduação em Ciências da Comunicação da ECA-USP

- Diretor-geral da Associação Brasileira de Comunicação Empresarial (Aberje)

- Vice-presidente da Associação de Comunicação Empresarial de Língua Portuguesa (Acelp) e da Associação de Comunicação Empresarial do Mercosul (Amerco)

- Autor dos livros 0 que é comunicação empresarial; A comunicação na pequena empresa; Tudo é comunicação; e Relações Públicas na construção da responsabilidade histórica e no resgate da memória institucional das organizações

- Colunista do site Terra Magazine e diretor editorial da Revista de Comunicação Empresarial e da Revista MSG

- Membro da Arthur W. Page Society, da IABC, da PRSA e da Abrapcorp

- paulonassar@usp.br 
Um dos impactos da tecnologia no modo de vida no começo do século XXI foi tornar o ambiente social mais complexo e exigir, nas organizações, comunicadores mais sofisticados nos seus saberes, o que não foi seguido pela universidade, que cria especialistas nas partes da Comunicação. Já nos anos 1980 falava-se em comunicação integrada e em pensamento sistêmico como visão de mundo; na década de 1990, viu-se a extrapolação das responsabilidades das organizações até nos anos 2000, quando esses conceitos começaram a ser substituídos e a memória e a história passaram a ser a base da narrativa empresarial.

PALAVRAS-CHAVE: COMUNICAÇÃO ORGANIZACIONAL • COMUNICAÇÃO INTEGRADA • RESPONSABILIDADE HISTÓRICA • MEMÓRIA EMPRESARIAL

\section{Abstract}

One of the impacts of technology on the lifestyle of the early 21st century was to cause the social environment to become more complex and to create in organizations a demand for communicators who are more sophisticated in their knowledge, but this action was not followed by the university, as it still produces specialists in Communication seen in a functional manner. In the 1980s people spoke of integrated communication and systemic thinking with a worldwide outlook; speeches and communicational actions associated with the responsibilities of organizations predominated from the 1990s decade up to the year 2000 and beyond, when these concepts started to be replaced and memory and history became important elements of organizational narrative.

KEYWORDS: ORGANIZATIONAL COMMUNICATION • INTEGRATED COMMUNICATION • HISTORICAL RESPONSIBILITY • BUSINESS MEMORY

Resumen

Uno de los impactos de la tecnología en el modo de vida a inicios del siglo XXI fue volver el ambiente social más complejo y exigir, en las organizaciones, comunicadores más sofisticados en sus saberes. Sin embargo, la universidad no siguió esta tendencia y todavía forma especialistas en partes de la Comunicación. Más tarde, ya en la década de 1980, se hablaba de la comunicación integrada y del pensamiento sistémico como visión de mundo; en la década de 1990 se produjo una extrapolación de las responsabilidades de las organizaciones hasta el año 2000, momento en el que esos conceptos comenzaron a ser sustituidos y la memoria y la historia pasaron a ser la base de la narrativa empresarial.

PALABRAS CLAVE: COMUNICACIÓN ORGANIZACIONAL • COMUNICACIÓN INTEGRADA • RESPONSABILIDAD HISTÓRICA • MEMORIA EMPRESARIAL 
$\mathrm{N}$ os últimos quarenta anos, as mudanças ocorridas no mundo, originadas por diversos fatores, sobretudo como reação aos impactos da tecnologia no dia a dia das pessoas, provocaram, naturalmente, profundas transformações na maneira de homens e mulheres viverem e de se relacionarem. Ao olhar especificamente para o comunicador nesse período, percebe-se que o ambiente em que ele transita tornou-se mais complexo e ele, o comunicador organizacional, foi instado a ser um profissional mais culto sofisticado, dotar-se de outros saberes, apurar sua visão de mundo, aguçar sua sensibilidade política, embora, não raro, se identifique um olhar ainda preconceituoso sobre ele, na universidade e em parte de sociedade, especialmente aquela afetada pela publicidade, pelos modismos, pelas celebridades e pelo sensacionalismo. A academia não soube responder, com a transformação do seu modo de ensinar, a essa necessidade de sofisticação, imposta pelas mudanças do ambiente. Manteve quase inalterado o processo de ensino fragmentado, avesso à mestiçagem de conhecimentos, em compartimentos do saber, que produz especialistas em partes, as quais fazem o todo da comunicação e da vida. Isso obriga a que o profissional busque, por iniciativa própria ou com o apoio da empresa, sua empregadora, a complementação, nem sempre objetiva, da sua formação, de maneira a atuar satisfatoriamente no desempenho de suas funções e corresponder às expectativas que se tem de um comunicador no começo do século XXI. A ex-diretora de Comunicação Institucional da Vale, Olinta Cardoso (VALOR SETORIAL, 2008, p. 24), explica, por exemplo, que "entender bem os locais onde a empresa opera já não passa mais por feeling. É preciso diagnóstico de questões políticas, sociais, antropológicas, institucionais".

A revolução promovida pela tecnologia e pela democracia, que alçou o cidadão a um novo patamar e inverteu a relação de poder entre ele e a empresa ou instituição, entre ele e a mídia, destacou o comunicador no cenário organizacional como aquele capaz de estabelecer e cultivar relacionamentos duradouros entre a organização e as pessoas. A tecnologia e a democracia derrubaram de fato os velhos processos comunicacionais e a centralidade das organizações como únicas produtoras de narrativas.

\section{Já havia quem enxergasse mais longe}

Já na década de 1980, Margarida M. Krohling Kunsch (1986) falava da "comunicação integrada" (expressão que, na atualidade, de forma oportunista, alguns publicitários brasileiros querem apresentar para a sociedade como invenção de última hora), aquela que, a partir de um planejamento bem estruturado, unifica a mensagem concebida em ambiente multidisciplinar e, estrategicamente, a integra para obter melhor e mais efetivo resultado. Era o sinal de que aquele comunicador produtor de mídia, cumpridor de ordens de cima para baixo, perdia espaço e surgia um novo profissional alinhado com uma visão relacional. Ou seja, a integração da comunicação se dá pela 
política, pelo planejamento, pela inteligência e não pela operação de mídias para-jornalísticas. Antes dessa época, a vasta obra do inesquecível Cândido Teobaldo de Souza Andrade também já lançava as bases de uma visão sistêmica, cada dia mais presente, na abordagem da comunicação como uma ação integrada de meios, formas, recursos, canais e intenções. Uma nova maneira de olhar o mundo, oposta ao mecanicismo que, desde o início dos anos 1900, foi o modelo de produção adotado no mundo todo, com suas velhas linhas de produção, tão bem ilustrado pelo operário vivido por Charles Chaplin no filme Tempos modernos, de 1936.

A partir de meados dos anos 1980 vivemos, felizmente, a volta gradual da democracia, o que provocou um forte impacto no modo de a empresa se comunicar.

Na década de 1990, depois de passar um longo período de economia praticamente fechada e altas taxas de inflação, o Brasil fez sua abertura comercial e experimentou a estabilização macroeconômica, que o levaram a integrar-se à economia mundial, à modernização tecnológica e ao incremento da produtividade. Nassar e Figueiredo (1975) trataram, já nessa época, da abrangência da atividade da Comunicação Empresarial, como uma das consequências da redemocratização do País, que levou, por exemplo, o deslocamento do foco da comunicação - antes dirigido aos empregados da empresa - para uma faixa amplificada, que passou a incluir a sociedade e seus atores. Naquele ambiente, em que a concorrência e o maior acesso ao capital estrangeiro estimularam os produtores a aumentar a competitividade, viu-se o crescimento de recursos investidos na produção, por conta do aumento da demanda doméstica a partir da redução da inflação e da substituição de importações e incremento das exportações. Segundo Eraldo Carneiro (VALOR SETORIAL 2008, p. 30), gerente de Planejamento e Gestão da Comunicação Institucional da Petrobras, complementa que, "em grande parte, o que alavancou a função da comunicação foi a economia dos intangíveis. Uma função importante pelo valor que gera para o negócio”.

Certa "comoditização" dos produtos e serviços e um mercado concorrencial agressivo provocaram a necessidade de as empresas se diferenciarem uma das outras aos olhos da sociedade e do consumidor, que passava a protagonizar a cena, começava a se conscientizar de seu poder e de seus direitos. Essa busca pela diferenciação desaguou na extrapolação das responsabilidades da empresa. Afinal, já não bastava seguir as leis, pagar os impostos, assinar a carteira de trabalho dos empregados e cumprir o objeto do contrato social da empresa registrado na Junta Comercial. Era preciso ir além das responsabilidades comerciais, tomar para si parte da solução dos problemas sociais cuja competência é classicamente do Estado. Viu-se uma flagrante invasão do público pelo privado, diante da inoperância do governo nas aflições sociais, culturais e ambientais dos brasileiros. Muitas atrocidades foram cometidas por empresários em nome do social, muitos interesses foram satisfeitos com a manipulação da boa-fé dos consumidores e o uso das criancinhas como massa 
de manobra. Como no dito popular, "muita reverência foi feita com chapéu alheio" e muita saliva foi gasta nos discursos sociais empolados e vazios para encobrir interesses privados, tentar disfarçar a incoerência das ações pirotécnicas do chamado "marketing social".

\section{Para além do contrato}

A exploração excessiva e pouco ética das responsabilidades extramercadológicas por uma considerável parcela de empresas, provocou o desgaste desse recurso retórico e andou abalando algumas reputações. Mas entrávamos na década de 2000, em que estamos, e apareceu em substituição à responsabilidade social empresarial um conceito novo, até hoje não totalmente compreendido, na esteira de um assunto que tem rendido muito espaço e visibilidade: o aquecimento global e, relacionado com ele, a sustentabilidade. A palavra já dá sinais de fadiga pelo uso exaustivo, inadequado, irresponsável e interesseiro. Apesar das deficiências de compreensão do que envolve um comportamento empresarial, e pessoal, em prol da sustentabilidade ou o que represente a emissão e o sequestro de carbono, o que é factível e o que é ficção, "conversa para boi dormir", porque a economia não pode parar, muitos se têm beneficiado e gerado bastante alegria para seus acionistas, às custas da inocência ou ignorância das pessoas.

Mas nesta década também vimos integrar-se ao composto da Comunicação Organizacional as narrativas baseadas no mundo simbólico das organizações, o uso de relatos orais, a memória dos empregados, das comunidades e dos consumidores, entre outros, o resgate dos mitos de origem e dos ritos de cada empresa, a valorização da História, da Psicologia Organizacional, da Antropologia. Marco Antônio Lage (VALOR SETORIAL, 2008, p. 24), diretor de comunicação corporativa do Grupo Fiat no Brasil e da Fiat Automóveis para a América Latina, conta que "foi um grande desafio integrar toda a política de comunicação estratégica com a área de Publicidade, que tem conceito e prioridade muito mais comercial”. O que explica o antropólogo Rodolfo Guttilla (VALOR SETORIAL, 2008, p. 36), diretor de Assuntos Corporativos e Relações Governamentais da Natura, ao dizer que, "a fronteira entre todas as áreas de uma grande empresa é muito movediça. O que realmente faz a diferença é o fato de sermos administradores do simbólico".

Empresas perceberam o valor de suas histórias e investiram no seu resgate e na sua sistematização. Criaram seus Centros de Memória, promoveram exposições itinerantes, como o Grupo Águia Branca, com sede no Espírito Santo, ganhador do Prêmio Aberje 2008 na categoria "Responsabilidade histórica e memória empresarial” (COMUNICAÇÃO EMPRESARIAL, 2009, p. 28), que recriou seu Centro de Memória dentro de um ônibus e rodou 10 mil quilômetros em seis estados e 45 localidades para mostrar sua história de sessenta anos de serviços de transporte aéreo e rodoviário de passageiros, comércio e logística. 


\section{Olhar no futuro}

Neste ambiente de novas demandas relacionais, já se discute, como valorização do âmbito da recepção, a abolição da expressão "público interno" para designar os empregados como alvo da comunicação empresarial. "Comunicação 'interna' não existe. Tanto o público interno como todos os outros estão cada vez mais críticos, cada vez mais conhecem o negócio e conversam entre si”, diz Malu Weber (VALOR SETORIAL, 2008, p. 32), gerente-geral de Marca e Comunicação Corporativa da Votorantim, seguida por Elisa Prado (VALOR SETORIAL, 2008, p. 28), diretora de Comunicação da Tetra Pak para a América Central e a América do Sul, ao afirmar que, "no fundo, os funcionários formam a opinião da empresa. Cada vez mais há encontros com todos, e não só os da liderança, para explicar aonde exatamente a empresa quer chegar". A expressão geográfica "Comunicação Interna” é cada vez mais abolida do vocabulário dos comunicadores organizacionais. Afinal, cada vez mais integrados pela tecnologia digital e pela vontade de viver em ambiente democrático, todos pretendem estar neste mundo (NASSAR, 2009a). E os intermediários parecem perder poder, no mundo da Comunicação. Vê-se enfraquecerem os que fazem o meio de campo entre as chamadas fontes de informação e a sociedade, as agências tradicionais, os veículos de comunicação de massa tradicionais - jornais, revistas, rádios, televisões, filhos de uma era em que para se comunicar de maneira ampla eram necessários aparatos tecnológicos identificados a olho nu: grandes antenas retransmissoras ou grandes instalações industriais para abrigar impressoras enormes. Propagandear, vender, entreter, comunicar era sinônimo de especialista, muita máquina e muito fio. A comunicação agora é intensiva, muito mais leve, mais software. Dispõe de grande oferta de mídias novas, inimigas de especialistas e intermediários. Hoje você acorda com o canto dos blogs e o trinado do twitter. A era exclusiva do rádio, da televisão e da imprensa escrita passou. $\mathrm{O}$ agora comunicativo são todas as eras mais o tempo do eu-mídia, em que pessoas, empresas e instituições são donas das suas próprias mídias. Um tempo de relações públicas intensivas, em que todos são jornalistas, publicitários e relações-públicas (NASSAR, 2009b).

Pesquisa realizada em agosto de 2008 pelo Instituto de Pesquisa da Associação Brasileira de Comunicação Empresarial (Aberje) e publicada pelo jornal Valor, em 20 de outubro de 2008, na sua Revista Setorial, indica o perfil do comunicador de hoje: a grande maioria dos entrevistados tem entre 25 e 44 anos de idade e $65 \%$ ocupam cargo de gerência, coordenação ou supervisão na empresa em que trabalham. Um terço dos entrevistados formou-se em Jornalismo, 19,9\% em Administração de Empresas e 17\% na área de Marketing e Comunicação. As mulheres são mais da metade dos entrevistados, ocupando $67 \%$ dos cargos de supervisão e $50 \%$ dos de gerência. A Comunicação Organizacional vem se tornando cada vez mais mestiça, o que explica a presença, na área, de antropólogos, advogados, sociólogos, filósofos, historiadores e até engenheiros (VALOR SETORIAL, 2008a, p. 18-20). 


\section{Para concluir}

Essa complexidade crescente que se vê na Comunicação Empresarial não é apolínea, mas dionisíaca, como na definição nietzschiana. Ela mistura tudo, festa com luto, riso com choro, porque a comunicação não tem que harmonizar nada. Ela deve ser capaz de navegar no caos.

\section{Referências}

COMUNICAÇÃ̃ EMPRESARIAL. Memória itinerante. Comunicação Empresarial, Aberje, a. 19, n. 70, p. 28, 2009.

KUNSCH, Margarida M. Krohling. Planejamento de relações públicas na comunicação integrada. 1. ed. São Paulo: Summus, 1986.

NASSAR, Paulo. 0 lugar da comunicação. Terra Magazine, 18 jul. 2009a. Disponível em: <http://terramagazine.terra.com.br/ interna/0,0l3879089-El6786,00-0+lugar + da + comunicacao.html>.

0 (en)canto do blog. Terra Magazine, 20 jun. 2009b. Disponível em: <http://terramagazine.terra.com.br/ interna/0,,0l3834992-El6786,00-0+encanto + do + blog.html> .

NASSAR, Paulo; FIGUEIREDO, Rubens. 0 que é comunicação empresarial?. São Paulo: Brasiliense, 1995.

VALOR SETORIAL Caminhos e pontes para o diálogo. Valor Setorial - Comunicação Corporativa, p. 22-36, out. 2008.

Cargo requer novo perfil profissional. Valor Setorial - Comunicação Corporativa, p. 17-21, out. 2008a. 